\title{
Rola przedsiębiorczości imigrantów w rozwijaniu postaw przedsiębiorczych kraju przyjmującego
}

DOI: $10.47050 / 65591760.328-339$

Agnieszka Brzozowska

Coraz większe wyzwania związane z migracjami sprawiają, że kraje przyjmujące stają przed koniecznością tworzenia takich rozwiązań, które możliwie najbardziej efektywnie pozwolą imigrantom zaadaptować się na rynku pracy. Jak pokazują badania, przedsiębiorczość imigrantów może być właśnie takim rozwiązaniem, ma ona bowiem - oprócz pozytywnego wpływu na integrację imigrantów - korzystne oddziaływanie na przedsiębiorczość autochtonów. W artykule skupiono się na znaczeniu przedsiębiorczości imigrantów w rozwoju przedsiębiorczości społeczności kraju przyjmującego.

\section{_ Słowa kluczowe:}

przedsiębiorczość imigrantów

integracja imigrantów

kompetencje przedsiębiorcze imigrantów 


\section{The role of immigrant entrepreneurship in the development of entrepreneurship in the host countries}

DOI: $10.47050 / 65591760.328-339$

Agnieszka Brzozowska

In the face of increasing challenges related to migration, it is important for the host countries to build solutions that will make immigrants adapt in the labor market in the most effective way. As research shows, immigrant entrepreneurship could be one of the solutions. In addition to the positive impact on the integration of immigrants, it turns out that it often has a positive impact on entrepreneurship among native people. The text focuses on the importance of immigrant entrepreneurship in the development of community entrepreneurship in the host country.

Keywords:

immigrant entrepreneurship

integration of immigrants

entrepreneurial skills of immigrants 


\section{Wprowadzenie}

Zjawisko migracji i przedsiębiorczości imigrantów jest bardzo złożone. Analiza literatury przedmiotu z krajów z długą historią imigracyjną pozwala spojrzeć na możliwe kierunki prowadzenia polityki imigracyjnej w państwach, które dopiero stają się krajami docelowymi dla imigrantów, i jej możliwe konsekwencje dla rozwoju przedsiębiorczości. Dzięki temu, że badania dotyczące przedsiębiorczości imigrantów od wielu lat są prowadzone równolegle w różnych krajach, można zebrać ciekawy materiał, ukazujący między innymi, w jaki sposób przedsiębiorcze inicjatywy imigrantów wpływają pozytywnie na ogólny dobrobyt krajów przyjmujących i na samo zjawisko przedsiębiorczości (Kushnirovich 2015). Najdłuższą tradycję badawczą w tym obszarze mają przede wszystkim kraje będące najczęstszymi celami migracji ludności, czyli Stany Zjednoczone, Kanada, Australia oraz państwa Europy Zachodniej (Fairlie 2008, Portes, Borocz 1989, Saxenian 2002b). W ostatnich latach również $w$ Polsce zainteresowanie tematem przedsiębiorczości migrantów przybrało na sile, między innymi z powodu zwiększenia się skali imigracji i zauważalnych inicjatyw przedsiębiorczych cudzoziemców (Andrejuk 2016, Brzozowski 2017, Glinka, Brzozowska 2015).

Wiele badań wskazuje na to, że porównując osoby urodzone w kraju zamieszkania z osobami, które urodziły się za granicą, można zauważyć, że wśród tych drugich odsetek osób prowadzących swoje firmy jest większy (Borjas 1986, Lofstrom 2002, Light, Rosenstein 1995). Robert W. Fairlie (2008) zauważa, że w Stanach Zjednoczonych imigranci chętniej zakładają firmy niż autochtoni. Może to wynikać z ich specyficznego podejścia do ryzyka i samej przedsiębiorczości, a także wyposażenia w takie kompetencje, które pozwalają podejmować odważne i niestandardowe decyzje (Berger 1991). Skoro imigranci byli w stanie zdecydować o emigracji, to założenie własnej firmy nie stanowi dla nich większego wyzwania. Evgueni Vinogradov i Eva Jenny Benedikte Jørgensen (2016) zauważają również, że imigranci częściej dostrzegają okazje związane z prowadzeniem biznesu na skalę międzynarodową, podejmując kooperację z partnerami zagranicznymi. Ponadto w Stanach Zjednoczonych imigranci są bardziej zauważani w branżach wysokich technologii (Hart, Acs 2011) i biotechnologii (Stephan, Levin 2001), gdyż stanowią dużo większy odsetek wśród właścicieli tego rodzaju firm. 
Nie zawsze jednak własna firma jest dobrowolnym wyborem imigrantów. Zdarza się bowiem, że imigranci wybierają możliwość samozatrudnienia z braku możliwości znalezienia pracy etatowej (Zhou 2004), między innymi z powodu bariery językowej, efektu "szklanego sufitu", braku kwalifikacji uznawanych w kraju przyjmującym. Nierzadko przyczyną niemożności znalezienia pracy są różne przeszkody instytucjonalne w polityce państwa przyjmującego, które dyskryminują imigrantów jako potencjalnych pracowników (Kloosterman 2010). Polityka ta opiera się na bardzo krótkowzrocznym myśleniu ze strony państwa, które nie docenia potencjału cechującego imigrantów prowadzących swoje firmy. Międzynarodowa wiedza, kontakty z krajem pochodzenia, znajomość innej kultury czy doświadczenie międzynarodowe imigrantów można byłoby wykorzystywać w celu sprzedaży produktów i usług w innych krajach, a także zwiększenia znaczenia kraju przyjmującego w handlu międzynarodowym (Oviatt, McDougall 1994). Są jednak państwa, w których politycy zauważają znaczenie imigrantów w gospodarce, oferują im specjalne wizy i ułatwienia, zachęcając tym samym obcokrajowców do prowadzenia swoich firm właśnie w tym kraju (Fairlie, Lofstrom 2015).

Ogólnie przedsiębiorczość imigrantów jest uznawana za realne rozwiązanie problemu braku pracy dla imigrantów, pozwala im uzyskiwać satysfakcjonujące wynagrodzenie, sprzyja rozwojowi gospodarczemu kraju przyjmującego i jest ważnym czynnikiem integracji imigrantów (Heilbrunn, Kushnirovich 2008, Riva, Lucchini 2015).

\section{Wpływ przedsiębiorców imigrantów na rynek kraju przyjmującego}

Problem migrantów jest w społeczeństwach krajów przyjmujących często traktowany z rezerwą, zdarza się jednak, że i z dużą niechęcią. Tymczasem wiele wyników badań świadczy o tym, że przedsiębiorczość imigrantów wpływa pozytywnie na rozwój gospodarczy kraju, w którym jest ona prowadzona, i buduje regionalne przewagi konkurencyjne oraz sprzyja innowacjom (Cummings 1980, Hunt i in. 2010). Na przykład w Stanach Zjednoczonych imigranci prowadzący firmy w branżach wymagających wysokich kwalifikacji w Dolinie Krzemowej odgrywają bardzo ważną rolę w gospodarce, między innymi pobudzając innowacje (Saxenian 2002a). 
Pozytywny wpływ firm zakładanych przez imigrantów na rynek pracy kraju przyjmującego może przejawiać się w trzech formach:

$\rightarrow$ tworzenie możliwości zatrudnienia dla osób, które nie są dostrzegane przez główne rynki pracy,

$\rightarrow$ zmniejszanie konkurencji z rodzimymi pracownikami,

$\rightarrow$ rozwijanie tych modeli przedsiębiorczości, które zapewnią imigrantom możliwość uzyskiwania większych zarobków (Zhou 2004).

Zoltan J. Acs i Catherine Armington (2004), podejmując analizy tekstów Paula M. Romera (1990) i Paula Krugmana (1991), stworzyli model, w którym tłumaczą, w jaki sposób wzrost zatrudnienia w regionie jest powiązany z trzema kluczowymi czynnikami: przedsiębiorczością, skutkami aglomeracji i kapitałem ludzkim. Ich analiza empiryczna wykazała, że nowe firmy są ważniejszymi motorami wzrostu ekonomicznego niż istniejące firmy w regionie, a rozpowszechnianie wiedzy jest kluczowym składnikiem pobudzającym lokalną przedsiębiorczość.

Warto również wspomnieć o roli kulturowych cech i uwarunkowań imigrantów, które pozytywnie kształtują kapitał społeczny w kraju przyjmującym (Chand, Ghorbani 2011, Peredo, Chrisman 2006). Bo Carlsson i Statton Jacobson (1997) sugerują, że doświadczenie przez imigrantów funkcjonowania na płaszczyźnie dwóch kultur może zwiększać „przestrzeń poszukiwań" okazji do podejmowania przedsięwzięć biznesowych. Imigranci mogą na przykład dostrzec potencjalne rynki lub relacje $w$ łańcuchu dostaw w ich kraju ojczystym lub w kraju przyjmującym, które nie są widoczne dla tych, którym brakuje takiego tła. Powiązania z ojczyzną zwiększają natężenie współpracy z krajem przyjmującym, co zwiększa produktywność (Peri 2012).

W Stanach Zjednoczonych, które mają długą i bogatą historię migracji, sami przedsiębiorcy zwracają uwagę na zalety funkcjonowania imigrantów przedsiębiorców w społeczeństwie kraju przyjmującego i walczą o bardziej otwarte podejście do tej kwestii, szczególnie dla branż związanych z high-tech (Gates 2008, Herman, Smith 2009). Wyniki badań prowadzonych na firmach z sektora high-tech w Stanach Zjednoczonych wskazują, że przedsiębiorstwa prowadzone przez imigrantów nie różnią się pod względem wielkości czy efektywności działania od firm prowadzonych przez autochtonów, ale za to częściej działają na arenie międzynarodowej, budując szczególne relacje z przedsiębiorstwami z kraju pochodzenia, co zwiększa umiędzynarodowienie firm, pole ich 
działania i transfer wiedzy (Hart, Acs 2011). Jak bowiem pokazują badania, jednym z czynników sprzyjających umiędzynarodowieniu firm są osobiste orientacje ich założycieli (Wach 2015), duże znaczenie będzie więc miała osoba imigranta - założyciela firmy. Jeśli imigranci swobodnie komunikują się w języku kraju przyjmującego, to szybciej budują kontakty między grupą etniczną, z jakiej pochodzą, a społeczeństwem kraju, w którym żyją. Pozwala to wykorzystać te połączenia do zwiększenia kreatywności działania i angażowania wysoko wykwalifikowanych pracowników niezależnie od kraju pochodzenia. Obecność wysoko wykwalifikowanych imigrantów w Stanach Zjednoczonych powoduje wzrost poziomu innowacyjności technologicznej (Hunt, Gauthier-Loiselle 2010) oraz liczby rejestrowanych przez nich patentów (Wadhwa i in. 2007). Typ przedsiębiorczości, który polega na prowadzeniu działalności biznesowej w kraju przyjmującym i w kraju rodzinnym, jest nazywany przedsiębiorczością transnarodową (Vertovec 2004). Unikalnym zasobem takich przedsiębiorców jest rozumienie sposobu funkcjonowania klientów kraju ojczystego i kraju przyjmującego (Brzozowski, Cucculelli, Surdej 2014), co pozwala rozwinąć przedsiębiorczość międzynarodową.

Podsumowując, przedsiębiorczość wydaje się bardzo dobrym sposobem integracji społeczno-ekonomicznej imigrantów (Constant, Zimmermann 2004). Może to potwierdzić choćby przedsiębiorczość drugiego pokolenia imigrantów, którzy dzięki edukacji w kraju przyjmującym, rozległej siatce kontaktów, także z autochtonami, braku barier językowych i znajomości kultury kraju przyjmującego, aktywnie uczestniczą w rynku głównym (Jones i in. 2000, Rusinovic 2008).

Zdarza się jednak także, że prowadzący działalność gospodarczą imigranci mogą wypierać rodzimych przedsiębiorców z rynku, choć dotyczy to głównie firm, które nie rokują dużych przychodów (Fairlie, Meyer 2003), prawdopodobnie zatem i tak by nie przetrwały. Warto podkreślić, że analizy wskazują raczej, że wraz z migracjami z czasem zwiększa się ogólny poziom samozatrudnienia w kraju przyjmującym (Antecol, Schuetze 2007) i innowacyjność (Cummings 1980). Może to świadczyć, że w ogólnej perspektywie przedsiębiorczość migrantów mobilizuje do tworzenia firm o większym potencjale.

\section{Kultura przedsiębiorcza}

Kluczową rolę w rozwijaniu przedsiębiorczości należy przypisać osobom, które swoją postawą inicjują aktywność przedsiębiorczą. Duch przed- 
siębiorczości jest kształtowany dzięki kulturze przedsiębiorczej całej społeczności, którą tworzą jednostki. Jeśli indywidualni członkowie społeczności wspierają postawy przedsiębiorcze i same się charakteryzują takim podejściem, to innym łatwiej się zainspirować takim sposobem funkcjonowania. Imigranci przedsiębiorcy dokładają swoją cegiełkę do budowania postaw przedsiębiorczych w kraju przyjmującym. Współistnienie grup przedsiębiorczych mobilizuje i motywuje innych do rozwijania aktywności przedsiębiorczej.

Ponadto kultura - obejmująca wartości, przekonania czy styl życia - jest transferowana przede wszystkim w obrębie podstawowej komórki społecznej, jaką jest rodzina (Gray 1998). Tradycja prowadzenia własnej firmy jest mocno zakorzeniona w rodzinie (Hout, Rosen 2000). Oznacza to, że prowadzący firmy imigranci będą przekazywali swoim dzieciom postawę przedsiębiorczą, zaszczepiając kolejnym pokoleniom iskrę przedsiębiorczości. Nieprzypadkowo Stany Zjednoczone, kraj imigrantów, są uważane za miejsce, w którym szczególnie mocno można odczuć kulturę przedsiębiorczości (Galambos 2018). Proces ten trwał jednak wiele lat, a dziś możemy obserwować jego rezultaty, między innymi patrząc na szeroko opisywaną Dolinę Krzemową. Ponadto imigranci, którzy zakładają swoje firmy, są przykładem twórczej destrukcji (Schumpeter 1950), która sprawia, że w społeczeństwie są uwalniane pokłady kreatywności i przedsiębiorczości. Są ruchem, który zmienia obecny stan równowagi i mobilizuje do zmian, poszukiwania nowych rozwiązań.

\section{Zakończenie}

Biorąc pod uwagę, że imigranci są grupą, która najczęściej decyduje się na zakładanie własnych firm, jednocześnie zaś jej przedstawiciele tworzą rozwiniętą siatkę kontaktów, można założyć, że przedsiębiorcy ci powinni być jednym z ważniejszych źródeł pobudzenia wzrostu gospodarczego kraju przyjmującego. Na pewno przedsiębiorczość imigrantów zmienia dynamikę funkcjonowania firm w kraju przyjmującym, co sprawia, że wszyscy przedsiębiorcy muszą szukać nowych form zaistnienia na rynku, to z kolei pozytywnie może wpływać na rozwój kreatywności i kompetencji przedsiębiorczych. Przedsiębiorcy pochodzący z innego kraju łączą różne kultury i sieci społeczne, sprawiając, że społeczeństwo przyjmujące staje się zróżnicowane. Korzyści ekonomiczne wynikające z różnorodności kulturowej mogą być rozmaite, 
między innymi wzbogacenie bazy społeczno-ekonomicznej, stworzenie zróżnicowanej podaży talentów na rynku pracy lub zwiększenie możliwości kreatywnych społeczeństwa (Jacobs 1961, Floryda 2002). Ponadto potencjał w umiędzynarodowieniu, jakim odznaczają się imigranci, może pomóc w przezwyciężaniu obecnych problemów ekonomicznych (Zioło 2006). Migranci, wykazując specyficzne podejście do przedsiębiorczości i ryzyka z tym związanego, mogą pobudzać ogólnego ducha przedsiębiorczości w społeczeństwie, w którym funkcjonują. Przy dobrej integracji w kraju przyjmującym można liczyć na kooperację z autochtonami, co również korzystnie będzie oddziaływać na ogólny rozwój przedsiębiorczości. 


\section{Bibliografia}

$\rightarrow$ Acs, Z., Armington, C. (2004), The impact of geographic differences in human capital on service firm formation rates, "Journal of Urban Economics", 56, s. 244-278.

$\rightarrow$ Andrjeuk, K. (2016), Vietnamese in Poland: How does ethnicity affect immigrant entrepreneurship?, „Asian and Pacific Migration Journal”, 25 (4), s. 379-400.

$\rightarrow$ Antecol, H., Schuetze, H.J. (2007), Immigration, Entrepreneurship and the Venture Start-Up Process [w:] S.C. Parker, Z.J. Acs, D.R. Audretsch (red.), International Handbook Series on Entrepreneurship, t. 2, Boston: Kluwer Academic Publishers.

$\rightarrow$ Berger, B. (1991), The Culture of Modern Entrepreneurship [w:] B. Berger (red.), The Culture of Entrepreneurship, San Francisco, CA, s. 13-32.

$\rightarrow$ Borjas, G. (1986), The Self-Employment Experience of Immigrants. „Journal of Human Resources", 21, s. 487-506.

$\rightarrow$ Brzozowski, J. (2017), Immigrant Entrepreneurship and Economic Adaptation: A Critical Analysis, "Entrepreneurial Business and Economics Review", 5 (2), s. 159-176.

$\rightarrow$ Brzozowski, J., Cucculelli, M., Surdej, A. (2014), Transnational ties and performance of immigrant entrepreneurs: The role of home-country conditions, „Entrepreneurship \& Regional Development”, 26 (7-8), s. 546-573.

$\rightarrow$ Carlsson, B., Jacobson, S. (1997), Diversity creation and technological systems: A technology policy perspective [w:] C. Edquist (red.), Systems of innovation, London: Pinter, s. 266-294.

$\rightarrow$ Chand, M., Ghorbani, M. (2011), National culture, networks and ethnic entrepreneurship: A comparison of the Indian and Chinese immigrants in the US, „International Business Review”, 20, s. 593-606.

$\rightarrow$ Constant, E., Zimmermann, K.F. (2004), The Making of Entrepreneurs in Germany: Are Native Men and Immigrants Alike?, "IZADiscussion Paper Series", 1440, Bonn: IZA. 
$\rightarrow$ Cummings, S. (1980), Self-Help in Urban America: Patterns of Minority Business Enterprise. New York: Kenikart Press.

$\rightarrow$ Fairlie, R.W. (2008), Estimating the contribution of immigrant business owners to the U.S. economy, "SBA Office of Advocacy Research Summary", 334, Washington, D.C.: SBA.

$\rightarrow$ Florida, R. (2002), The rise of the creative class. New York, NY: Basic Books.

$\rightarrow$ Galambos, L. (2018), The Entrepreneurial Culture and the Mysteries of Economic Development, „Essays in Economic and Business History”, 36 (1), s. 290-320.

$\rightarrow$ Gates, B. (2008), Testimony before the U.S. House of Representatives, Committee on Science and Technology, www.microsoft.com/presspass/exec/billg/ speeches/2008/congress.mspx, (dostęp: 11.03.2019).

$\rightarrow$ Glinka, B., Brzozowska, A. (2015), Immigrant Entrepreneurs: in Search of Identity, "Entrepreneurial Business and Economics Review”, 3 (4), s. 51-76.

$\rightarrow$ Fairlie, R.W. (2008), Estimating the Contribution of Immigrant Business Owners to the U.S. Economy, Washington, D.C.: U.S. Small Business Administration, Office of Advocacy.

$\rightarrow$ Fairlie, R.W., Lofstrom, M. (2015), Immigration and Entrepreneurship [w:] B. Chiswick, P. Miller (red.), Handbook on the Economics of International Immigration, Amsterdam: Elsevier, s. 877-911.

$\rightarrow$ Fairlie, R.W., Meyer, B.D. (2003), The effect of immigration on native self-employment, „Journal of Labor Economics”, 21 (3), s. 619-650.

$\rightarrow$ Gray, C. (1998), Enterprise \& Culture, London: Routledge.

$\rightarrow$ Hart, D., Acs, Z. (2011), High-Tech Immigrant Entrepreneurship in the United States, „Economic Development Quartely", 25 (2), s. 116-129.

$\rightarrow$ Heilbrunn, S., Kushnirovich, N. (2008), Impact of ethnicity on financing of immigrant businesses, "International Journal of Business and Globalization", 2 (2), s. 146-159.

$\rightarrow$ Herman, R.T., Smith, R.L. (2009), Immigrant, Hoboken, NJ: Wiley.

$\rightarrow$ Hout, M., Rosen H.S. (2000), Self-Employment, Family Background, and Race, „Journal of Human Resources”, 35 (4), s. 670-692.

$\rightarrow$ Hunt, J., Gauthier-Loiselle M. (2010), How Much Does Immigration Boost Innovation?, "American Economic Journal: Macroeconomics”, 2 (2), s. 31-56.

$\rightarrow$ Jones, T., Barrett, G., McEvoy, D., Rath, J. (2000), Market potential as a decisive influence on the performances of ethnic minority business [w:] J. Rath (red.), Immigrant Businesses: The Economic, Political and Social Environment, London: Macmillan, s. 37-53. 
$\rightarrow$ Kloosterman, R. (2010), Matching Opportunities with Resources: A Framework for Analyzing (migrant) Entrepreneurship from a Mixed Embeddedness Perspective, „Entrepreneurship and Regional Development”, 22 (1), s. 25-45.

$\rightarrow$ Krugman, P. (1991), Increasing returns and economic geography, "Journal of Political Economy", 99, s. 483-499.

$\rightarrow$ Kushnirovich, N. (2015), Economic Integration of Immigrant Entrepreneurs, „Entrepreneurial Business and Economics Review”, 3 (3), s. 9-27.

$\rightarrow$ Ley, D. (2006), Explaining variations in business performance among immigrant entrepreneurs in Canada, „Journal of Ethnic \& Migration Studies", 32 (5), s. 743-764.

$\rightarrow$ Light, I.H., Rosenstein, C.N. (1995), Race, ethnicity, and entrepreneurship in urban America. New York, NY: Aldine de Gruyter.

$\rightarrow$ Lofstrom, M. (2002), Labor Market Assimilation and the Self Employment Decision of Immigrant Entrepreneurs, „Journal of Population Economics”, 15 (1), s. 83-114.

$\rightarrow$ Ndofor, H.A., Priem, R.L. (2011), Immigrant entrepreneurs, the ethnic enclave strategy, and venture performance, „Journal of Management”, 37, s. 790-818.

$\rightarrow$ Oviatt, B., McDougall, P. (1994), Toward a theory of international new ventures, "Journal of International Business Studies", 25 (1), s. 45-64.

$\rightarrow$ Peredo, A., Chrisman, J. (2006), Toward a theory of community-based enterprise, "Academy of Management Review", 31, s. 309-328.

$\rightarrow$ Peri, G. (2012), The Effect of Immigration on Productivity: Evidence from U.S. States, „Review of Economics and Statistics", 94, s. 348-358.

$\rightarrow$ Portes, A., Borocz, J. (1989), Contemporary immigration: Theoretical perspectives on its determinants and modes of incorporation, „International Migration Review", 23, s. 606-630.

$\rightarrow$ Riva, E., Lucchini, M. (2015), The Effect of the Country of Birth of the Owner on Business Survival. Evidence from Milan Metropolitan Area, Italy, "Journal of Ethnic and Migration Studies", 41 (11), s. 1794-1814.

$\rightarrow$ Romer, P. (1990), Endogenous technological change , Journal of Political Economy", 98, s. 71-102.

$\rightarrow$ Rusinovic, K. (2008), Moving between markets? Immigrant entrepreneurs in different markets, "International Journal of Entrepreneurial Behaviour \& Research", 14 (6), s. 440-454.

$\rightarrow$ Saxenian, A. (2002a), Silicon valley's new immigrant highgrowth entrepreneurs, „Economic Development Quarterly", 16, s. 20-31.

$\rightarrow$ Saxenian, A. (2002b), Brain circulation: How high-skill immigration makes everyone better off, "The Brooking Review", 20, s. 28-31. 
$\rightarrow$ Schumpeter, J.A. (1950), Capitalism, Socialism and Democracy, New York: Harper \& Brothers Publishing.

$\rightarrow$ Stephan, P.E., Levin S.G. (2001), Exceptional contributions to US science by the foreign-born and foreign-educated, "Population Research and Policy Review", 20 (1-2), s. 59-79.

$\rightarrow$ Vertovec, S. (2004), Migrant transnationalism and modes of transformation, „International Migration Review”, 38 (3), s. 970-1001.

$\rightarrow$ Vinogradov, E., Jørgensen, E.J.B. (2016), Differences in international opportunity identification between native and immigrant entrepreneurs, "Journal of International Entrepreneurship", 15 (2), s. 207-228.

$\rightarrow$ Wach, K. (2015), Entrepreneurial Orientation and Business Internationalisation Process: The Theoretical Foundations of International Entrepreneurship, „Entrepreneurial Business and Economics Review", 3 (2), s. 9-24.

$\rightarrow$ Wadhwa, V., Saxenian, A.L., Rissing, B.A., Gereffi, G. (2007), Education, Entrepreneurship and Immigration: America's New Immigrant Entrepreneurs, cz. 2, Duke University, Berkley and Ewing Marion Kauffman Foundation.

$\rightarrow$ Zhou, M. (2004), Revisiting ethnic entrepreneurship: Convergencies, controversies, and conceptual advancements, „International Migration Review", 38 (3), s. 1040-1074.

$\rightarrow$ Zioło, Z. (2006), Rola przedsiębiorczości w podnoszeniu konkurencyjności społeczeństwa i gospodarki, „Przedsiębiorczość - Edukacja”, 2, s. 10-17. 